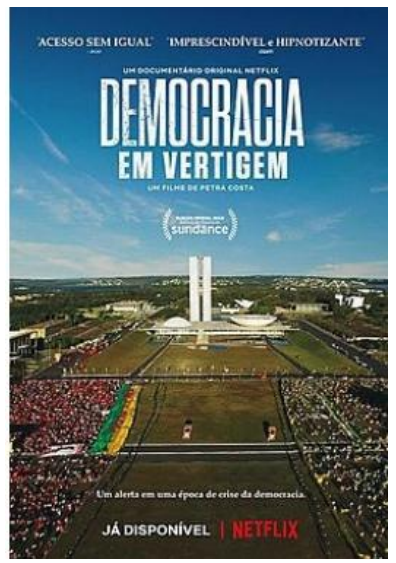

\author{
DOCUMENTÁRIO DEMOCRACIA EM \\ VERTIGEM, Roteiro: COSTA, Petra. Direção: \\ COSTA, Petra; NATASEGARA, Joanna; PAVAN, \\ Tiago; BORIS, Shane. 2019, $121 \mathrm{MIN}$. \\ CLASSIFICAÇÃO: 12 ANOS.
}

\title{
REENUNCIANDO DEMOCRACIA EM VERTIGEM: SOB AS LENTES DE BAKHTIN E O CÍRCULO
}

\author{
Eliete Correia dos Santos* \\ Wilder Kleber Fernandes de Santana**
}

O Documentário Democracia em Vertigem, sob direção e roteiro de Petra Costa, estreou mundialmente no Festival de Sundance e foi lançado pela plataforma Netflix em junho de 2019, com duração de 121 min e classificação de 12 anos.

Ana Petra Costa, filha dos militantes Manoel Costa e Marília Andrade, neta de um dos fundadores da construtora Andrade Gutierrez, nasceu em 8 de julho de 1983, na cidade de Belo Horizonte- MG. É autora do curta Olhos de Ressacas (2009) que mostra um retrato sobre o amor e o envelhecer sob o olhar de seus avós Vera e Gabriel, assim como criadora dos filmes: Elena (2012), que fala sobre o sonho de sua irmã de ser atriz e seu suicídio, Olmo e a Gaivota (2014), em que retrata as complexidades da maternidade.

A cineasta brasileira Petra Costa recebeu, pelo documentário Democracia em Vertigem, em Buenos Aires, o Prêmio Democracia, organizado pelo Centro Cultural Caras y Caretas; também foi escolhida como a "Personalidade Destacada da América Latina"; em setembro de 2019 - a publicação americana Indiewire já havia colocado a produção de Petra Costa como um dos cinco favoritos para a indicação ao Oscar na categoria de documentários. Analisado pelos jornalistas americanos como um alerta sobre a emergência da extrema-direita, citado no jornal New York Times, na lista dos dez melhores do ano,

\footnotetext{
* Professora da Universidade Estadual da Paraíba (UEPB) da Pós-graduação em Formação de Professores e colaboradora da Pós-graduação em Linguagem e Ensino da UFCG; Doutora em Linguística pela Universidade Federal da Paraíba (UFPB) e Pós-doutora em Educação Contemporânea pela Universidade Federal de Pernambuco (UFPE), PNPD/Capes; E-mail: professoraeliete@ hotmai.com

** Bolsista Capes. Doutorando e Mestre em Linguística pelo Programa de Pós-graduação em Linguística (Proling) da Universidade Federal da Paraíba (UFPB). Mestre em Teologia pela Faculdade Teológica Nacional (FTN) e Especialista em Gestão da Educação Municipal pela Universidade Federal da Paraíba (UFPB) . E-mail: wildersantana92@gmail.com
} 
como um documentário sobre o colapso político brasileiro, uma "crônica da traição cívica e do abuso de poder". ${ }^{1}$

O filme (não-fictício) apresenta gravações pessoais e de sua família, além de imagens exclusivas de fatos sobre a política brasileira. Costa começa contando um pouco de sua vida que coincide com o início do período de redemocratização do Brasil. É narrada, por exemplo, a influência de seus pais, que (sobre)viveram na ditadura militar e com muita luta conseguiram ainda almejar um pouco do Brasil que tanto sonhavam, trazendo para o cenário atual, desde a primeira candidatura do presidente Luiz Inácio Lula da Silva doravante Lula (em 1989) até a sua vitória (em 2002). Aborda o impeachment da presidente Dilma Rousseff, das peças e personagens no meio deste processo. A maneira de como foi apresentado pela mídia e a sua responsabilidade diante das apurações dos fatos ocorridos ao longo de cada época relatada no documentário.

No entanto, antes de prosseguirmos no empreendimento desta resenha, faz-se imprescindível mencionar os subsídios teórico-metodológicos de nossos dizeres, ou seja, a partir de que perspectiva tecemos nossos comentários. Baseamo-nos nas propostas dialógica e sociológica dos estudiosos e pesquisadores Mikhail Bakhtin (1895-1975), Valentin N. Volóchinov (1895-1936) e Pável N. Medviédev (1891-1938), integrantes do Círculo de Bakhtin.

Um dado interessante é o modo de se expressar da autora Petra Costa, que não nega a ideologia que defende, mas se posiciona ideologicamente (MEDVIÉDEV, 2016[1928]), instaurando-se axiologicamente (BAKHTIN, 2006 [1979]) e demonstrando possuir excedente de visão em relação a todo um contorno de acontecimentos éticos (BAKHTIN, 2010 [1920-24]), ou seja, do domínio da cultura humana e da historicidade dos fatos. Utiliza-se de uma narrativa com um tom reflexivo e dramático, na medida em que faz uso de tempo psicológico que se efetiva por emoções, situações, sentimentos, que determinam essa passagem do tempo individual e interno, formando uma narrativa através de memórias e lembranças como uma digressão dos fatos políticos do país e de sua vida particular.

Inicialmente, o documentário expõe uma cena que se expande a partir do interior de um carro, o qual está rodeado por fotógrafos e repórteres. Em continuidade, é informado, pelos jornalistas, um prazo para que o ex-presidente Lula se apresente, ao passo que, ao fundo é perceptível o sindicato dos metalúrgicos do $\mathrm{ABC}$, com muitas pessoas ao redor que tencionam impedir que o ex-presidente saia a caminho da prisão. Após Lula se despedir de seus companheiros políticos e amigos, outra cena se apresenta com uma manifestação diferente, a qual comemora a decisão do juiz, ao credibilizarem o seu ato. Ao explanar o Palácio da Alvorada, Petra narra de forma breve a origem do nome do Brasil e de sua sua relação com a cor vermelha, e perpassa assuntos como a facilidade do tráfico, a desvalorização da vida dos escravos, e toda a repressão concretizada durante o período escravagista.

Toda essa reenunciação histórica é extremamente importante para o processo de compreensão responsiva-ativa (BAKHTIN, 2006 [1979]) do curta por parte dos interlocutores, os leitores que estão assistindo ao filme. Bakhtin, em O problema do texto na linguística, na filologia e em outras ciências humanas aponta para princípios dialógicos da linguagem como essenciais para a interdiscursividade entre concepções ideológicas em

\footnotetext{
${ }^{1}$ Informações disponíveis em https://www.brasil247.com/cultura/cineasta-brasileira-que-filmou-historia-dogolpe-ganha-premio-sobre-democracia. Acesso em 17 de setembro de 2019.
} 
amplas esferas da atividade humana. Em mesma perspectiva político-sociológica, Medviédev (2016 [1928], p. 49-50), em O método formal nos estudos literários, assevera que "[t]odos os atos individuais participantes da criação ideológica são apenas os momentos inseparáveis dessa comunicação e são seus componentes dependentes e, por isso, não podem ser estudados fora do processo social que os compreende como um todo". Em outras palavras, Medviédev compreende os sentidos histórico e ideológico de cada campo da atividade humana como essenciais à consciência individual dos seres humanos, posto que essa consciência se dá no plano da alteridade. É nesse direcionamento argumentativo que "os atos ideológicos e todo seu "significado ideal" não estão apenas em uma descrição simplória e individual dos fatos acontecidos, "nem no mundo isolado das ideias e dos sentidos puros, mas no material ideológico disponível e objetivo, na palavra, no som, no gesto, na combinação das massas, das linhas, das cores, dos corpos vivos, e assim por diante" (MEDVIÉDEV 2016 [1928], p. 49-50).

Em continuidade à narrativa fílmica, é-nos apresentado que o nascimento da democracia tem seu aparecimento com o primeiro golpe militar, que após 21 anos de ditadura, conseguiu ser restaurada. A autora registra que seus pais passaram parte da ditadura de 1964 de forma clandestina em militância, momento em que foram presos. Após não muito tempo, estes começaram a viajar disfarçados, na organização de movimentos que envolviam estudantes e de trabalhadores.

Todos esses descortinamentos de teor histórico tem valor imprescindível ao discurso mobilizado pela autora do filme, pois condiciona aos expectadores e analistas terem acesso às condições efetivas de produção, ainda que haja pontos de vista em torno dos atos enunciativos. Logo, na primeira parte do texto Crítica da arte e estética geral, Bakhtin infere que "Nenhum valor cultural, nenhum ponto de vista criador pode e deve permanecer no nível da simples manifestação, do fato puro de ordem psicológica e histórica" (BAKHTIN, 2010 [1924], p. 16).; na ótica discursiva do filósofo, somente em asserções semânticas da cultura há possibilidades de superar o cientificismo do valor cultural. Paralelo a isso, é perceptível um cuidado em narrar os fatos e situar os expectadores das condições sociohistóricas que permitiram tais acontecimentos, uma vez que, para que se dê a compreensão responsiva ativa por parte dos leitores, é sempre preciso levar "em consideração o campo aperceptivo da percepção do meu discurso pelo destinatário: até que ponto ele está a par da situação, dispõe de conhecimentos especiais de um dado campo cultural da comunicação" (BAKHTIN, 2016, p. 63-64, destaque do autor).

De forma semelhante, quando Petra Costa narra que algumas mudanças no cenário político só ganham concretude no final dos anos 70, a partir do momento em que o sindicato dos operários declara greve, tendo como líder Lula, com seus 33 anos de idade, essas informações são constitutivas de todos os acontecimentos. Isso nos concatena aos estudos que Bakhtin empreendeu sobre o cronotopo, ou seja, as condições espaçotemporais que são tão importantes à compreensão dos sujeitos. Isso conduz o filósofo a afirmar que "[o]s índices do tempo transparecem no espaço, e o espaço reveste-se de sentido e é medido com o tempo" (BAKHTIN, 2006 [1979], p. 233).

Registra-se no documentário que os interesses políticos de Lula floresceram quando este visitou o Congresso Nacional, e percebeu que apenas dois parlamentares faziam parte da classe trabalhadora. Então, passa a liderar, após um tempo, a criação do partido dos trabalhadores, o que impulsiona sua candidatura nas eleições de 1989, seguidas dos anos 1994, 1998 e 2002, sendo esta última a única em que teve vitória. A narrativa empreende 
que no discurso de posse de Lula no Congresso, este relata que, apesar dos avanços do Brasil em diversas áreas no setor econômico, tais atos não foram suficientes para tirar o país da fome.

Nesse sentido, o curta explana o modo como Lula apresenta Dilma, sua sucessora, a qual ganha as eleições para presidência com a mesma aliança feita por Lula com o PMDB a condição de Dilma seria ter como seu vice, o líder do partido, Michel Temer. A construção de Dilma se dá como uma guerrilheira durante a ditadura militar, a qual foi presa aos 22 anos de idade, tendo sofrido muitas torturas.

Toda essa recorrência à historicidade dos fatos por meio de teor estético-artístico, no caso específico do plano fílmico, nos remete ao que Volóchinov desenvolve em $A$ palavra na vida e a palavra na poesia: introdução ao problema da poética sociológica (1926) sobre a importância do método sociológico extra-artístico. Na ótica do estudioso soviético, "A arte é eminentemente social [...] na arte o que não é alheio atua sobre o que é alheio, e uma formação social influencia a outra" (VOLÓCHINOV, 2013 [1926], p. 74). É nesse sentido que a palavra na vida nunca se centrará em si mesma, mas sobretudo tem seu surgimento em situações extra-verbais, conservando seus vínculos reais e concretos com a história e a memória sociais (VOLÓCHINOV, 2013 [1926]; MEDVIÉDEV, 2016 [1928])

A palavra escolhida pela autora está em consonância com a empatia, com a concordância ou discordância de seu auditório, com sua relação ao seu objeto do enunciado, em relação ao herói ${ }^{1}$. O auditório e o herói são participantes constantes do evento criativo e pela mediação da forma artística, o criador promove o assumor de uma posição ativa com respeito ao conteúdo. (VOLOCHINOV, 2017 [1929]), mas o ouvinte afeta a interrelação do criador e do herói. Por exemplo, no documentário, a crítica levantada à origem de como o "Golpe" foi construído, é narrada em um tom que busca esclarecer que a ação da presidente Dilma Rousseff, em retirar cargos importantes do PMDB e forçar os bancos a reduzirem as taxas de juros causaram uma desestabilidade na economia e queda em sua popularidade. Costa relata que a presidente tenta recuperar sua credibilidade e aprova diversas medidas anticorrupção, uma delas a delação premiada. Nesse cenário, a autora enfatiza que a Petrobrás, que em pouco tempo tinha sido alvo de uma espionagem pela agência nacional de segurança do EUA, é investigada pela Lava Jato que descobre uma teia de corrupção existente, interligando a empresa, empreiteiras e os principais partidos políticos.

Embora a presidente não tenha intervido nas investigações, ela é muito criticada por isso, o que acabaria custando sua posição política. Petra aponta que Rousseff, por uma pequena diferença consegue vitória sobre o seu principal adversário, Aécio Neves, que tinha o apoio das empreiteiras. Enfatiza que Aécio e o partido dele não aceitam a vitória de Dilma e pedem uma auditoria que obtém o mesmo resultado. Segundo a autora, a insatisfação leva-o a defender o impeachment da presidente. Esta passagem é bem sigificativa, porque causou muita polêmica aos leitores do documentário, pois, de maneira indireta, a construção do discurso deixa claro como a mobilidade, a diversidade, a pluralidade de usos da língua e de sentidos são formados e causam reações diversas sobre a mesma realidade.

O modo de construir sentido ocorre no processo de interação, no qual a palavra possui um acento apreciativo, ora reiterando ora alterando sua consistência significativa. É

\footnotetext{
1 A palavra "Herói" na obra Discurso na vida e discurso na arte, de Volochinov/Bakhtin (1976), é compreendida como objeto do enunciado, o tópico, o assunto, aquilo do que se fala.
} 
esse acento apreciativo ou avaliativo que dá vida à palavra, e ele muda conforme o contexto. Uma mesma palavra pode, ainda, adquirir sentidos diferentes conforme a entoação expressiva, assim como a enunciação, que também possui uma orientação apreciativa. Para Volochinov (2017 [1929]), sem acento apreciativo não existe palavra. Um exemplo disso e do discurso que mobiliza o documentário, é a obra a Resistência ao golpe de 2016 (PRONER et al., 2016) que contém 103 textos, entre artigos e entrevistas de vários autores com perspectivas políticas diferenciadas, mas que se juntaram para resistir contra o golpe na ocasião em curso no Brasil. Os enunciados relatam do papel do STF à atuação da mídia, das "pedaladas fiscais" aos meandros do Poder Legislativo, do papel dos atores políticos internacionais aos bastidores da Lava Jato, da crise de representatividade à ofensiva golpista. A palavra vai acumulando os sentidos das suas diversas utilizações ou na prática viva da língua. $\mathrm{O}$ acento dá o tom da conversa ou orienta para o sentido da enunciação. É às entoações que se devem as apreciações, e a estas devemos as significações, que são formadas no horizonte do interlocutor.

Em seu relato, a autora apresenta uma outra voz divergente de forma mais singela, por isso recebeu muitas críticas nas redes sociais, em vídeos publicados no YouTube que caracterizam o documentário como mentiroso e comunista. Uma dessas passagens muito criticada é sobre a abordagem da autora quanto a mensagens espalhadas por grupos de direita pelas mais diversas redes sociais, defendendo o sentimento anticorrupção e transformando em uma movimentação "anti PT". Costa ressalta que, além de contar com a mídia para transmitir e divulgar cada detalhe dessas manifestações, o processo de impeachment foi aberto como retaliação vindo do então presidente da câmara dos deputados Eduardo Cunha, que não conseguiu apoio do governo nem do PT e era investigado por ocultar milhões de dólares de suborno em bancos na Suíça. A narrativa se estende com detalhe da votação a favor do impeachment, e a presidente Dilma sendo retirada do poder de forma ilegítima. Narra também que a Lava Jato investiga o expresidente Lula na recebimento de um triplex como propina e expõe que o juiz Sérgio Moro, sem possuir provas, determina que Lula então seria culpado. Destarte, a construção do enunciado vai se constituindo a partir de um ponto de vista que comunga relatos pessoais e sociais da autora. Vale dizer que "autor, herói e ouvinte em parte alguma se fundem numa só massa indiferente - eles ocupam posições autônomas, eles são na verdade "lados"” (VOLOCHINOV/BAKHTIN, [1926]1976, p. 14) de um evento artístico com uma estrutura social específica.

Por isso, acreditamos que o documentário gerou uma Agenda Setting ${ }^{1}$ no Brasil e no mundo bastante significativa, pelas variadas mídias e redes sociais. A obra foi um espaço, segundo a perspectiva da autora, de apresentar uma antinomia dos discursos contraditórios que mostra que toda verdade pode ser descontruída por outro discurso, por outra informação. Tudo que é feito com palavras pode ser desfeito por palavras, uma antinomia de colocação de dois discursos de oposição, cada um produzindo seu ponto de vista distinto, cada um projetando uma tal realidade.

A estrutura do enunciado do filme exala, a partir dos arquivos pessoais e fatos políticos, o valor axiológico e ideológico da autora, por isso não há como deixar de admitir as especificidades coercivas em cada imagem, comentário, entrevista que apresentam seu

\footnotetext{
1 "A ideia teórica central é que os elementos proeminentes na imagem da mídia tornam-se proeminentes na imagem da audiência. Aqueles elementos enfatizados na agenda da mídia acabam tornando-se igualmente importantes para o público.” (McCOMBS, 2009, p. 111).
} 
próprio modo de orientação para a realidade e refrata a realidade à sua própria maneira. Assim, os signos podem refletir sobre o mundo, mas sempre fazemos de modo refratado que está intrinsicamente ligado ao ideológico de uma época ou grupo social, com verdades e interpretações diferenciadas, definindo um tom apreciativo no plano ideológico e discursivo.

Isso quer dizer que todo corpo físico que passa a ter um significado exterior à sua natureza, tem a função de signo ideológico, não só por refletir uma realidade material, mas também por refratar essa ou outra realidade. Na ótica de Volóchinov, toda e qualquer refração ideológica do ser, em processo de formação, independente da natureza de seu material significante, é acompanhada de uma refração ideológica verbal, como fenômeno obrigatório (VOLOCHÍNOV, 2017 [1929]). A palavra segue os atos de compreensão e interpretação da vida humana como signo ideológico no fluxo da interação verbal, ganha diferentes significados de acordo com o contexto em que está inserida e revela um espaço em que os valores fundamentais de uma dada sociedade se explicitam e se confrontam.

A consciência constitui-se de signos que entrelaçam signos sem interrupção, formando uma rede ideológica estabilizada nas formas de compreensão da realidade sóciohistórica e adquire forma e existência de forma sígnica, criados por um grupo social organizado no fluxo de suas relações sociais (VOLOCHÍNOV, 2017 [1929]). Nesse sentido, para alguns membros do círculo de Bakhtin, não há como significar sem refratar na dinâmica da história, pois esse significar é marcado pela diversidade de experiências dos grupos humanos, pelo confronto de interesses sociais nos limites da luta de classes. Esse ser histórico não é determinado por uma ordem de nascimento apenas biológica, mas sobretudo através de faíscas semânticas, feixes de sentido históricos, não apenas nele se reflete, mas também se refrata (VOLOCHÍNOV, 2017 [1929]).

Pensamos que a leitura do documentário é um exercício que possibilita a construção do ponto de vista do aluno, ao concordar ou não, mas também oportuniza o diálogo e o respeito às diferenças que deveriam vigorar. Não há como, nós professores de linguagem, deixarmos de colocar na pauta de nossas ações como fazer os jovens desenvolverem o senso crítico e sinalizar a persuação pelas redes sociais que (de)informa mais que informa com Fakes que prometem resolver todos os problemas e a corrupção do Brasil. Contrapontos distintos e muitas vezes contraditórios, o princípio que sempre trabalhou a democracia é a discussão exaustiva das opiniões divergentes a tomadas de decisões, alguns preferem, neste momento, calar as vozes de seus oposicionistas, mas o caminho da humanidade no que se refere à linguagem mostra que os momentos de seu apogeu coincidem com os períodos de maior liberdade, de maior segurança, de maior paz.

Certamente, a leitura do documentário possibilita um debate associado a outras temáticas que incitam os alunos a pensarem na temporalidade dos fatos, tais como as tentativas de derrubar a Lei de Acesso à informação e ampliar o sigilo de documentos são preocupações legítimas. Entre junho de 2017 e maio de 2018, mais de 73 mil documentos foram colocados sob sigilo pelo governo brasileiro, mas há pouca transparência em relação aos motivos dessa classificação.

$\mathrm{Na}$ posição de pesquisadores no terreno da linguagem, alertamos que é urgente articular o ensino estético-artístico à concepção dialógica do discurso. Ao inserirmos esse modelo metodológico-analítico como exemplo, certamente acreditamos que despertará o senso crítico de sujeitos leitores e expectadores a se inserirem na cadência ininterrupta da história, com pontos de vista plurais, cujas vozes se constituem alteritariamente. Com certo tom de (in)acabamento, esperamos que essa investigação possa estimular outros sujeitos a inserirem 
sua voz ativa com produções e práticas docentes que veiculem sementes germinadoras do ensino dialógico.

\section{Referências}

BAKHTIN, M. M. O problema do texto na linguística, na filologia e em outras ciências humanas. In: BAKHTIN, M. M Estética da Criação Verbal. [tradução feita a partir do russo; tradução Paulo Bezerra]. 5. ed. São Paulo: Martins Fontes, 2006 [1979].

BAKHTIN, M. M. Os gêneros do discurso. Tradução, posfácio e no-tas de Paulo Bezerra. São Paulo: 34, 2016 [1979].

BAKHTIN, M. M. O problema do Conteúdo, do Material e da Forma na Criação Literária. (1924). In: Questões de literatura e de estética - A Teoria do Romance. Equipe de tradução (do rus-so) Aurora Fornoni Bernardini; José Pereira Júnior; Augusto Góes Júnior; Helena Spryndis Nazário; Homero Freitas de Andrade. 6. edição. Editora Hucitec - São Paulo, 2010. (1930-1934).

MCCOMBS, M. A Teoria da Agenda: a mídia e a Opinião. Rio de Janeiro: Vozes, 2009.

MEDVIÉDEV, P. N. O Método Formal nos estudos literários: introdução a uma poética sociológica. Tradutoras: Shei-la Camargo Grillo e Ekaterina Vólkova Américo. São Paulo: Contexto, 2016 [1928].

PRONER, Carol et al (orgs). A resistência ao golpe de 2016. Bauru: Canal 6, 2016. 425 p.

VOLOCHÍNOV, V. N. (Círculo de Bakhtin). Marxismo e fi-losofia da linguagem Problemas fundamentais do método sociológico na ciência da linguagem. Tradução de Sheila Grillo e Ekaterina Vólkova Américo - Ensaio introdutório de Sheila Grillo. 1. ed. São Paulo: Editora 34, 2017 [1929].

VOLOCHÍNOV, V. N. A palavra na vida e a palavra na poesia: introdução ao problema da poética sociológica, p.71-111. (1926). In: VOLÓCHINOV - Do círculo de Bakhtin. A construção da enunciação e outros ensaios. Trad. João Wanderley Geraldi. São Carlos: Pedro e João editores, 2013.

VOLOCHINOV [BAKHTIN]. Discurso na vida e na arte: sobre a poética sociológica. Trad. de Carlos Alberto Faraco e Cristóvão Tezza da edição inglesa de TITUNIK, I. R. "Discourse in life and discourse in art - concerning sociological poetics". In: Volochinov, V. N. Freudism. New York: Academic Press, 1976 [1926].

Recebido em 20 de novembro de 2019

Aceito em 29 de dezembro de 2019 